\title{
The Influence of Involvement and Awareness on UAE Women Attitude Towards Fashion Clothing
}

\author{
Hamza Salim Khraim ${ }^{1}$ \\ ${ }^{1}$ Faculty of Business, Al-Ahliyya Amman University, Amman, Jordan \\ Correspondence: Hamza Salim Khraim, Faculty of Business, Al-Ahliyya Amman University, Amman, Jordan.
}

Received: March 19, $2018 \quad$ Accepted: April 10, $2018 \quad$ Online Published: May 7, 2018

doi:10.5539/ijms.v10n2p76 URL: https://doi.org/10.5539/ijms.v10n2p76

\begin{abstract}
The landscape of fashion industry in UAE has changed and evolved over the years in unprecedented way. This study examines the influence of involvement and awareness on UAE women attitude towards fashion clothing. In addition, we will shed some light on fashion industry inside UAE. For collecting the required data, a self-administered survey was distributed for a convenience sample of female Emirati students resulting in 223 usable responses. Numerous statistical analysis tools were used, first factor analysis was conducted and followed by regression, in addition to items mean and frequency. The results indicate that women in UAE have a positive attitude towards fashion clothing. Self-confidence will increases by following fashion statement got the highest mean by respondents. Further, it was found that involvement has a significant influence on UAE women attitude towards fashion clothing. While awareness have no any influence on UAE women attitude towards fashion clothing.
\end{abstract}

Keywords: involvement, awareness, women, fashion attitude, fashion theory, UAE

\section{Introduction}

In recent decades, the fashion industry has been a major contributor to global economy development. It is considered as one of the world's largest consumer industries generating 1.5 trillion USD in annual apparel and footwear revenues in 2016, and it employs around 60 million people along its value chain (FashionUnited, 2016). McKinsey Fashion Scope (2017) projected that growth in 2017 will be expected to be in India and the United Arab Emirates. Despite the smaller size of the fashion industry in these countries, still there are interesting opportunities for growth, particularly compared with other emerging countries where foreign-exchange fluctuations and economic slowdowns have taken their toll on consumer spending, such as in Brazil and Russia. This growth is attributed to fact that people are becoming more conscious of the fashion and style trends. The importance of staying up to date with the latest trends and fashions has become a part of the lifestyle of most individuals. The Gulf Region is a geographical area that enjoys substantial purchasing power and a high discretionary income, with a steady booming market for luxury fashion (Marciniak \& Mohsen, 2014). In mature markets, like New York, Tokyo, and London in particular a woman will purchase an average of 3,000 fashion items in a lifespan, making the fashion industry one of the most pervasive of the design segments (MENA Design Outlook, 2015). Women attitude towards fashion in UAE is considered a very interesting subject for research since they show a unique dual behavior concerning fashionable traditional dress by pursuing Western luxury fashion trends and maintaining their own cultural and religious identity Trainer $(2015$, p. 6). The focus of this study will be on Women in UAE, which accounts for 49.3 percent of the national population, according to the 2015 Census. Women are considered at the forefront of the workforce in the UAE in both the government and private sector. Women in the UAE enjoy equal opportunities, like men, for work and investment to conduct their own businesses in all fields. More than ten thousand businesswomen in the country own and run their own businesses. The capital managed by women amounts to Dh12.5 billion (about US\$3.17 billion) invested in various fields, including trade, industry finance, real estate, tourism, and services (Al Roumi, 2007).

Sproles (1974) was the pioneer in exploring and developing fashion oriented consumer behavior theory, which has been widely used in several studies dealing with consumer decision making. According to Sproles (1974) fashion was defined as a culturally endorsed form of expression, in a particular material or non-material phenomenon, which is discernible at any given time and changes over time within a social system or group of associated individuals. If we compare any current definition for fashion with the one proposed by Sporles (1974) 
we can see that main core and meanings of his definition are still valid until nowadays. For example, (Solomon, 2007, p. 589 cited in Atik \& Firat, 2012) defined fashion as the process of social diffusion by which a new style (of fashion clothing) is adopted by some group(s) of consumer. Wilson (1985) described "fashion" as dress characterized by rapidly changing styles, relies on continuous consumption, and depends on certain technological advances. While sociologists and scholars identified fashion with two elements: 1) being accepted by many people and (2) its acceptance lasts for a relatively short period of time (Women's Wear Daily, 2015).

The main purpose behind this paper is exploring this potential huge market, by exploring women attitude towards fashion market. This research can unfold an important result in a part of the Arabian Gulf where the culture is conservative and complete opposite of that in the West. The aim of this research is to investigate women attitude in UAE towards fashion patterns. The growth of fashion industry in UAE and hosting many fashion events in Dubai is an indicator of the industry maturity. The main contribution of this research is to fill the gap in the fashion research about one of the most growing market, which is UAE, which can be very significant for local and international fashion companies to understand some of the female consumer behavior aspects regarding new fashion trends. Finally, after the introduction, the literature review section will highlight different trends in fashion as well study variables and empirical studies. Research methodology will clarify data collection method and sample, followed by results and discussions and finally conclusions.

\section{Literature Review}

In this section, we will cover different issues related to size and nature of fashion market in UAE, and try to highlight previous research on women attitude towards fashion, and the role of involvement and awareness in fashion.

\subsection{Women Attitude Towards Fashion Clothing}

Kacen (2000) demonstrate a historical fact that fashion has focused on female consumers. This fact has been supported by several studies, which found that women are more involved in fashion and clothing products than men (Browne \& Kaldenberg, 1997). Another research conducted by Chiger (2001) and Flynn et al. (2000) indicated that women are more involved in shopping and shop more often for clothing in general than men. Women generally find shopping more pleasurable than men and have a more positive attitude towards the browsing and social interaction that often follows with the buying procedure. Women associate buying with leisure, shopping plays an emotional, psychological and symbolic role. Furthermore, women spend twice as long time in a shop as men and the typical window-shopper is a woman (Kuruvilla et al., 2009). Rocha (2005) study found that women are more fashion concerned; they give more attention to their bodies and give higher consideration to clothes to express themselves with extremely higher level than men. Women also consider themselves more innovative when it comes to fashion and their behavior and position in society differs from men in relation to fashion (Hogg et al., 1998; Bakewell \& Mitchell, 2003).

In UAE, which is considered the most modernized Arab Gulf country, women have plenty of options concerning clothing, and can choose their clothing from a variety of excellent designers (Omair, 2009). Women in UAE apply the typical separation between public and private spaces. Women's dress and behavior is highly influenced by this separation of context. This separation centers on the idea that in the private space of the family home (or the home of a close relative or female friend), women have freedom of movement, self-presentation, and dress, as well as control over many household affairs, whereas the public spheres are male-dominated. Public spaces, and in particular public spaces full of men who are not close relatives, are areas that women approach with caution accompanied by family members. Based on the above literature, we can propose the following hypothesis:

H1: Women in UAE have a positive attitude towards fashion clothing.

\subsection{Involvement}

A major challenge facing involvement researchers lies in understanding involvement itself (O'Cass, 2004). Early research by Krugman (1965) on consumer involvement has been used by many researchers to investigate many important areas related to consumer behavior traits to be able to comprehend how they make their decisions (e.g., Kim, 2005; Michaelidou \& Dibb, 2006). More specifically fashion involvement literature is a growing research stream related with how important, meaningful and relevant fashion clothing is to the lives of consumers. It is a research stream dedicated to explain fashion clothing related consumption behaviors (O'Cass, 2004; Bloch et al., 2009). Previous research about fashion shows that women are more involved with fashion than men (Blakewell \& Mitchell, 2003; O'Cass, 2004). Research proves that consumer involvement can leads to a greater involvement in the purchase decision itself for durable and non-durable products. In more recent research by 
(O’Cass \& Choy, 2008) they found an important significant association between purchase decision involvement and fashion apparel. Based on the above literature, we can propose the following hypothesis:

H2: Involvement has a significant influence on women attitude towards fashion clothing.

Because fashion is primarily concerned with novelty (Evans, 1989), it is often considered to be an innovative way for fashion adopters to express their "self" to others. In addition, it has been noticed recently that Arab consumers residing in the United Arab Emirates show an importance of displaying their social symbols and wealth through wearing highly visible items, which portray their status. They follow the proverb, which states, "you are not what you wear but who you wear" (Vel et al., 2011, p. 4). They maintained that the UAE lifestyle is eventually changing and consumers today are more knowledgeable about products and what products best suit his or her image. UAE consumers are social oriented type of people and they have a need to maintain class and exclusivity in everything they do. Most of them are concerned with society approval and care about being approved and accepted by others. Many of these consumers come from a society where appearances matter and to gain society's approval. Based on the above mentioned literature, we can propose the following sub-hypothesis:

H2a: Involvement has a significant influence on women novelty for fashion clothing.

$\mathrm{H} 2 \mathrm{~b}$ : Involvement has a significant influence on fashion role in culture for women

$\mathrm{H} 2 \mathrm{c}$ : Involvement has a significant influence on modern-day women for fashion clothing.

H2d: Involvement has a significant influence on women orientation towards fashion clothing.

\subsection{Awareness}

Pioneer research done by (Tigert et al., 1976), described fashion awareness as the response of the individual to the new trends and styles. Women are more sensitive to clothing needs and possess a greater clothing awareness than men (Adjei et al., 2006). Khan et al. (2015) asserted that brand awareness should be an important aim of marketing program of fashion companies. While Delong et al. (2004) considered that if the consumers have knowledge about the brand, they appear to recognize it. It is generally approved that brand attitude is formed due to brand awareness. Only with brand awareness, consumers are likely to acquire the product. As such, brand awareness is an important factor to determine consumer attitude.

Women who are fashion conscious don't just look anywhere and everywhere or at anyone in the street to find the indicators of trends, but institutionalized elements in society serve a key role in their decision making (Atik \& Firat, 2012). Consumers talk to each other about new trends and styles, exchange information and give suggestions to each other, which makes social communication is the best tool for exchanging information on fashion (Goldsmith \& Clark, 2008). Fashion magazines and advertisements within the magazines are considered a reliable medium by consumers as a source for the latest trends, must haves within fashion, and are used as an inspiration for fashion purchases. Based on the above literature, we can propose the following hypothesis:

H3: Awareness has a significant influence on women attitude towards fashion clothing.

Based on the above hypothesis, we can propose the following sub-hypothesis:

H3a: awareness has a significant influence on women novelty for fashion clothing.

H3b: awareness has a significant influence on fashion role in culture for women

H3c: awareness has a significant influence on modern-day women for fashion clothing.

H3d: awareness has a significant influence on women orientation towards fashion clothing.

Based on the above literature review, the following theoretical framework is suggested for this study.

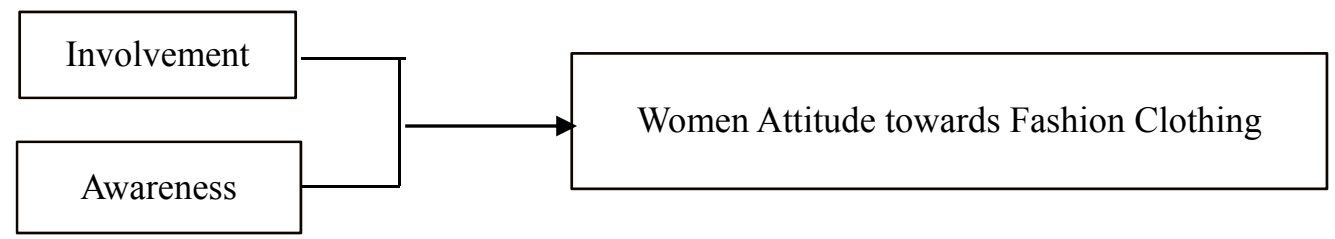

Figure 1. Theoretical framework 


\subsection{Fashion Market in UAE}

Based on Grail Research (2009), international fashion market is categorized into three groups; famous global fashion hubs (e.g., France, USA, and UK), Fast growing markets (e.g., Singapore, Russia and Brazil) and emerging fashion markets (e.g., UAE, China and India). The third type is considered as highest attraction point for international fashion companies nowadays (Sheth, 2011). The fashion industry in the UAE is unprecedented in its evolving landscape, which adapts to the latest trends and designs that cater for both native and international clientele. Emirati designers have realized that variety in fashion is a key to position the UAE as one of the major fashion capitals in the world. In 2013, Dubai Design and Fashion Council were established to assist in achieving its vision in 2020 to become number one global fashion hub (MENA Design Outlook, 2015, p. 14). Currently, UAE managed to leads the region and position itself as a global and regional fashion retail hub with a majority 28.3\% share of apparel revenues, followed more distantly by Saudi Arabia in second with $16.8 \%$ (MENA Design Outlook, 2015, p. 14). The Dubai Mall, which hosts 1,200 shops and boast "Fashion Avenue", recognized as the largest collection of luxury fashion brands under one roof anywhere in the world and hosting a wide array of brands. More than one million visitors attended the three-day Vogue Fashion Dubai Experience (VFDE) in 2014.

It is remarkable to say that consumers in UAE believe that they can display their social symbols and wealth through wearing highly visible items, which reflects an important issue such as social status. They are motivated to impress others with their ability to pay high prices for expensive and prestigious products (Vel et al., 2011). By using luxurious goods as symbols, they communicate meaning about themselves to others in society. UAE consumers view global luxury brands as symbols of prosperity and social status as do Western consumers. They believe that the more expensive the item they wear, the better impression they will give out to others in society (Vel et al., 2011).

\section{Empirical Studies}

Trainer (2015) did the most related papers to female Emirati student choices of fashion in the UAE. The study aimed to explore how those young female students engaged in identity construction via particular types of activities by which they actively engaged in "self-making" through behaviors and fashion. She found that many students wore very expensive brands underneath their abayas on a regular basis. Results show that fashion was important to the female university students. Results also show that women constantly expressed individuality, heterogeneity, and style, not only in the ways in which they wore the abaya and shayla, experimenting with colors, decorations, sheerness, costliness, etc., but also in their selections of what to wear under the abaya.

Busnaina (2014) in his paper aimed to explore the significance of brand identity vs. adaptation degree of the global fashion brands' offerings in Saudi Arabia as well as to identify Arab customers' perception towards global fashion brands' personality and image. The main contribution of this paper was empirically investigating the actual marketing practices of four overseas fashion brands (i.e., GUESS, Levi's Burberry and H\&M). Results show that adaptation is considered more applicable for global fashion brands in Saudi market, but that was not consistently across marketing implementations. Furthermore the researcher found that marketing adaptation in fashion may cause undesirable results and produce bad influence in Saudi market; it caused differences between the perceived brand image and the brand personality that are promoted by companies.

The primary purpose of Marciniak \& Mohsen (2014) paper was to explore the extent to which Arab women are a homogeneous group of consumers concerning perceptions and motivations to consume luxury fashion goods. The study's findings suggest that distinct value perceptions of luxury fashion among Arab females are evident, that is, this group of consumers is homogeneous in terms of prestige seeking behavior. Additional findings also show that Arab women, many of whom wear the abaya when in public, seek to pursue mutual socially conforming consumption behaviors through luxury fashion. In terms of practitioner implications, the findings support retail-marketing decisions concerning profiling distinct consumer groups of Arab females, which luxury marketers can target with discrete marketing communications.

While the purpose of (Omair, 2009) study was to explore how Arab women managers in UAE construct their social identities through the meanings that they themselves give to their clothing while pursuing managerial careers. The focus of analysis was on dress at the individual level, specifically focusing on dress as a symbol that individuals use to convey messages about themselves. Many important factors such as religion, economic development and socio-cultural which influence the mode of clothing for female managers in their working lives has been evaluated. Results of this study show that women in UAE are fully aware of the reasons for wearing their traditional clothes and what their dress communicates about them. Although Arab women in UAE are proud to wear their traditional dress, there is little diversity to be found in clothing choices. Women's clothing choices are done neither by women themselves nor by their men but it is the deeply rooted societal and cultural norms 
that dictate the "proper" clothing.

\section{Research Methodology}

\subsection{Sampling and Data Collection Procedure}

In order to get an in depth understanding of fashion clothing trends, a questionnaire was developed which included multiple close-ended questions regarding fashion clothing in UAE. Fashion involvement and awareness were measured based on previous literature. Fashion involvement was measured by using 6 items from O'Cass's (2000) and (Belton \& Clinton, 2007). While for fashion awareness, it was also measured by 6 items from Khan et al. (2015) and Wiedmann et al. (2009). In order to ensure the fittingness of the instrument it was pilot tested on a sample of students and the results indicated that the instrument is ready for further analysis. All of the multi-item scales used were five-point, Likert-type scale items, with responses ranging from 1 strongly disagree to 5 strongly agree. For collecting the required data, a self-administered survey was distributed for a convenience sample of 250 undergraduate female Emirati students who attend a mid-sized university in the University City of Sharjah with 1300 student, about 690 of them were female students. Out of 250 questionnaires, only 223 were usable and included in data analysis, while the remaining 27 questionnaire were disqualified. The size of sample is considered appropriate and it exceeds the minimum of 200 participants suggested by several researchers (Kline, 2011; Teo et al., 2013). Statistical Program for Social Scientists (SPSS 17.0) is used checking the relationship between the different variables. It's noteworthy to say that the majority of students who study in the evening program are working in the morning, and because of that many of them are working women. The sample is considered representative since it covers the biggest five emirates in the UAE.

\section{Results and Discussions}

The questionnaire consisted of four sections; the first section was about respondents' demographics, which include questions related to age, income, job type, marital status, and place of resident. The second section contained 14 questions about women attitude towards fashion clothing, while section three and four contained 6 questions each about fashion involvement and awareness respectively. Table 1 show respondent demographics which show that more than half (52.5\%) of respondent age was between 18 to 25 years old. Regarding income respondent were distributed among different categories with slight increase in the category with less than 10.000 Dirham's. While more than half of the respondent, (58.7\%) were single. About $44.1 \%$ were working in government sector, and finally more than half (53.8\%) were living at emirate of Sharjah. Regarding section 2, 3 and 4 Reliability coefficient alphas for variables were tested as shown in Table 2. Results show that reliability coefficient alpha for the three variables were above the minimum level accepted which is .70 as suggested by Nunally (1978). Loewenthal (1996) suggests that a reliability alpha value of 0.60 is also acceptable for scales with less than 10 items.

Table 1. Respondent demographics

\begin{tabular}{lll}
\hline Demographics & Frequency & Percent \\
\hline Age & 117 & \\
$18-24$ & 94 & 52.5 \\
$25-30$ & 12 & 42.2 \\
More than 30 & & 5.4 \\
Income & 69 & 33.9 \\
Less than $10000^{*}$ & 41 & 20.1 \\
10001-20000 & 44 & 21.6 \\
Mo000-30000 & 49 & 24.1 \\
More than 30001 & & \\
Marrital Status & 12 & 36.8 \\
Single & 131 & 58.7 \\
Divorced & 10 & 4.5 \\
Job Type & 70 & 31.5 \\
Private Sector & 98 & 44.1 \\
Govt. sector & 24 & 13.1 \\
Own business & 25 & 11.3 \\
No job & & \\
State of Resident & 120 & 53.8 \\
Sharjah & 36 & 16.1 \\
Dubai & 25 & 11.2 \\
Ajman & 30 & 13.5 \\
RAK & 12 & 5.4 \\
Abu Dhabi & & \\
\hline SD
\end{tabular}

Note. *: $1 \mathrm{USD}=3.85 \mathrm{UAE}$ Dh. 
Table2. Reliability coefficient alphas for variables

\begin{tabular}{llll}
\hline Scale & No. of items & Alpha & Mean \\
\hline Attitude towards fashion & 14 & 0.852 & 3.75 \\
Fashion Involvement & 6 & 0.731 & 3.47 \\
Fashion Awareness & 6 & 0.819 & 2.99 \\
\hline
\end{tabular}

\subsection{Hypothesis Testing}

For testing the first hypothesis, $t$ test has been done as shown in table 3 . The results show that all items are significant. The mean of the 14 items used to measure women attitude towards fashion in UAE has been calculated also as shown in Table 3. The overall mean for the 14 items was 3.752, which mean that women have a positive attitude towards fashion in UAE since we have a mean above 3 . Based on this result we can accept the first hypothesis that proposes that women in UAE have a positive attitude towards fashion clothing. Statement no. 2 which ranked first and got the highest mean with 4.28 focuses on self-confidence, while statement no. 3 ranked second and focuses on educated women acceptance of fashion. In the third position was statement no. 1 and talk about how fashion brings novelty to life. From these results we can see that fashion can contribute for women personality in terms of novelty and self-confidence. On the other hand women in UAE is not using fashion in getting attention of the other gender and by getting the lowest mean for this statement (3.59), it shows that UAE society still adhere to cultural values and morals.

Table 3. Mean and standard deviation and t-test for women attitude towards fashion clothing

\begin{tabular}{|c|c|c|c|c|c|c|}
\hline No. & Items & Mean & Std. Deviation & Rank & $\mathrm{t}$ & Sig. \\
\hline 1 & Fashion brings feeling of novelty in life. & 3.816 & 1.36471 & 3 & 41.75 & .000 \\
\hline 2 & Self-confidence increases by following fashion. & 4.287 & 1.09387 & 1 & 58.52 & .000 \\
\hline 3 & Educated women accept fashion faster. & 3.870 & 1.12952 & 2 & 51.16 & .000 \\
\hline 4 & Fashion and education are associated with each other. & 3.717 & 1.25777 & 5 & 44.13 & .000 \\
\hline 5 & Adopting fashion is not opposing to tradition. & 3.690 & 1.31116 & 7 & 42.03 & .000 \\
\hline 6 & There is a fear of looking traditional by not adopting fashion. & 3.686 & 1.21557 & 8 & 45.28 & .000 \\
\hline 7 & Fashion should be adopted only to the extent approved by the culture. & 3.704 & 1.16338 & 6 & 47.54 & .000 \\
\hline 8 & pursuing fashion is a sign of modernism & 3.677 & 1.20575 & 9 & 45.54 & .000 \\
\hline 9 & In modern life fashion is the key to success. & 3.670 & 1.23289 & 11 & 44.43 & .000 \\
\hline 10 & Working women give more attention to new changes in fashion. & 3.753 & 1.12193 & 4 & 49.95 & .000 \\
\hline 11 & Social media has a great role in adopting new fashion & 3.609 & 1.23584 & 13 & 43.62 & .000 \\
\hline 12 & Traditional clothing should be designed aligned with new fashion & 3.618 & 1.15197 & 12 & 46.91 & .000 \\
\hline 13 & Women within all age categories should follow fashion & 3.668 & 1.17681 & 10 & 46.54 & .000 \\
\hline \multirow[t]{2}{*}{14} & Fashion can help me in getting attention by other gender & 3.594 & 1.25133 & 14 & 42.06 & .000 \\
\hline & Total Mean & 3.752 & & & & \\
\hline
\end{tabular}

While for testing $\mathrm{H} 2$ and $\mathrm{H} 3$, and in order to an in depth understanding on women attitude towards fashion clothing, the 14 items were first factor analyzed. According to Brown (2006) exploratory factor analysis is generally used in the beginning process of scale development to construct validation. KMO was first tested to check data appropriateness for factor analysis. The KMO should range from 0.5 to 1.0 to deem appropriate. Results show KMO for our data is 0.790 and Bartlett's test was significant as well. Based on this result factor analysis was conducted. Items for women attitude towards fashion were analyzed using Factor Analysis followed by Varimax Rotation in order to capture the dimensionality of the construct (Sandra et al., 2017). As shown in Table 4, factor analysis created four factors with loading above .50, reliability test were done for the new factors, and all as shown in Table 4 were higher than the minimum accepted level. Items in factor one reflects novelty, since educated women will follow fashion trends based on the fact they understand why they wearing like that. Factor two represents the importance and role of culture in shaping attitude towards fashion, while factor three show modern-day women as a sign of modernism and success. Finally, factor four gives an idea regarding different issues concerning women orientation towards fashion.

The extracted four factors were used in subsequent analysis. Regression analysis was used to test the influence of fashion involvement and awareness on the four factors of women attitude towards fashion. For main hypothesis $\mathrm{H} 2$ and $\mathrm{H} 3$ the model itself was found to be significant $(\mathrm{F}=21.582, \mathrm{p}=.000)$. 
Table 4. Rotated factors from principles component analysis for women fashion attitude

\begin{tabular}{|c|c|c|c|c|}
\hline & Items & Loadings & $\begin{array}{l}\text { Variance } \\
\text { Explained }\end{array}$ & $\begin{array}{l}\text { Reliability } \\
\text { Test }\end{array}$ \\
\hline \multicolumn{5}{|c|}{ Factor 1: Novelty } \\
\hline 1 & Fashion brings feeling of novelty in life. & 0.704 & & \\
\hline 2 & Self-confidence increases by adopting fashion. & 0.739 & 21.88 & 0.662 \\
\hline 3 & Educated women accept fashion faster. & 0.584 & & \\
\hline 4 & Fashion and education are associated with each other. & 0.672 & & \\
\hline \multicolumn{5}{|c|}{ Factor 2: Fashion role in Culture } \\
\hline 5 & Adopting fashion is not opposing to tradition. & 0.829 & & \\
\hline 6 & There is a fear of looking traditional by not adopting fashion. & 0.842 & 14.18 & 0.801 \\
\hline 7 & Fashion should be adopted only to the extent approved by the culture. & 0.642 & & \\
\hline \multicolumn{5}{|c|}{ Factor 3: modern-day women } \\
\hline 8 & pursuing fashion is a sign of modernism & 0.614 & & \\
\hline 9 & In modern life fashion is the key to success. & 0.840 & 8.74 & 0.749 \\
\hline 10 & Working women give more attention to new changes in fashion. & 0.687 & & \\
\hline \multicolumn{5}{|c|}{ Factor 4: Fashion oriented women } \\
\hline 11 & Social media has a great role in adopting new fashion & 0.757 & & \\
\hline 12 & Traditional clothing should be designed aligned with new fashion & 0.831 & & \\
\hline 13 & Women within all age categories should follow fashion & 0.735 & 6.98 & 0.766 \\
\hline 14 & Women from all social class should show interest in fashion & 0.657 & & \\
\hline
\end{tabular}

Extraction Method: Principal Component Analysis.

Rotation Method: Varimax with Kaiser Normalization

Table 5. Regression analysis for testing $\mathrm{H} 2$ and $\mathrm{H} 3$

\begin{tabular}{llll}
\hline Hypothesis & Standardized beta $(\mathrm{t})$ & Significance level & Result \\
\hline $\mathrm{H} 2:$ Involvement $\rightarrow$ women Attitude & 6.567 & 0.000 & Accepted \\
$\mathrm{H} 2 \mathrm{a}:$ Involvement $\rightarrow$ Novelty & 6.188 & 0.000 & Accepted \\
$\mathrm{H} 2 \mathrm{~b}:$ Involvement $\rightarrow$ Fashion role in Culture & 2.956 & 0.003 & Accepted \\
$\mathrm{H} 2 \mathrm{c}:$ Involvement $\rightarrow$ Modern-day women & 3.561 & 0.000 & Accepted \\
$\mathrm{H} 2 \mathrm{~d}:$ Involvement $\rightarrow$ Fashion oriented women & 6.118 & 0.000 & Accepted \\
$\mathrm{H} 3:$ Awareness $\rightarrow$ women Attitude & 1.402 & 0.160 & Rejected \\
$\mathrm{H} 3 \mathrm{a}:$ Awareness $\rightarrow$ Novelty & 0.371 & 0.711 & Rejected \\
$\mathrm{H} 3 \mathrm{~b}:$ Awareness $\rightarrow$ Fashion role in Culture & 1.410 & 0.163 & Rejected \\
H3c: Awareness $\rightarrow$ Modern-day women & 1.916 & 0.517 & Rejected \\
$\mathrm{H} 3 \mathrm{~d}:$ Awareness $\rightarrow$ Fashion oriented women & 1.243 & 0.215 & Rejected \\
\hline
\end{tabular}

\section{Conclusions}

Due to the dearth of research in this area in UAE, this attempt is considered as a very important step towards understanding women attitude towards fashion clothing. Many interesting findings were obtained from this research. The aims were exploring women attitude towards fashion and analyzing the role of involvement and awareness on this attitude. Results show women have a positive attitude towards fashion since it will increase self-confidence and novelty for educated and working women, which support Trainer (2015) and Omair (2009) results. Results show also that there is significant influence of Involvement on women attitude towards fashion, and this result support Rahman et al. (2014) research. This study confirms that females have a greater orientation to involvement with fashion clothing. O'Cass (2004) comments that a major challenge facing fashion involvement research lies not only in understanding involvement itself, but also in understanding the role that fashion involvement plays along with other variables in guiding the formation of purchase and consumption patterns. Additional analysis can be done to test the relationship between demographic variable and involvement and their collective influence on fashion attitude. Third hypothesis was rejected. There was no significant influence for fashion awareness on women attitude towards fashion. This result is also in agreement with the empirical results of O'Cass (2004) and Vieira (2008). Fashion companies need to supply consumers with a convenient access to relevant fashion-related information to update them on new fashion trends on regular basis. 
This study can be very beneficial for fashion companies and retailers, because several market segments can be categorized. For example, clothes sold to business women need to be neat, elegant, and expensive to reflect their social status and because they aware of and willing to dress within the evolving styles of the fashion. Another segment is women working in the governmental sector. They wear and prefer the conservative appeal, although they are aware of the need to dress in expensive clothing. Third segment can be fashion involved, who try to keep updated with new trends, and they dress based on new fashion of the day and follow what is depicted on the fashion TV and magazines. The result shows also that second statement "self-confidence will increases by adopting fashion" scored the highest mean by respondents. As indicated by O'Cass (2004) Confidence is an example of a non-evaluative dimension and refers to the conviction with which the belief in decision-making ability and ability to choose the right brand is held. Results show also that in modern society like UAE, cultural and social influencers can influence consumers' attitude towards fashion. Fashion clothing plays not only the role of covering up and keeping warm but it is used to express ones identity and influence how others will perceive you and therefore plays an important role in today's society (O'Cass, 2000). This designate that women in UAE are value conscious concerning fashion as Western women, but with adherence to local cultural rules and trends.

Finally, for future research, it is much advisable to focus on some specific brands known to customers. In addition, the sample of this study consisted only from local UAE participant, it is highly recommended to include other nationalities as well. Other variables can very insightful in giving more information about female consumers in UAE such demographics. In addition, future research can focus on different levels of consumer involvement for different brands class. Another important issue, which we can tackle, is explore the influence of personality and values such as materialism on fashion involvement and attitude as well.

\section{References}

Atik, D., \& Firat, A. F. (2012). Fashion creation and diffusion: The institution of marketing. Journal of Marketing Management, 29(7), 836-860.

Al Roumi, M. M. K. (2007). Women in the United Arab Emirates: A Portrait of Progress. Minister of Social Affairs, at the UN General Assembly Debate, March 8, New York.

Adjei, M. T., Griffith, D. A., \& Noble, S. M. (2006). Drivers of local merchant loyalty: Understanding the influence of gender and shopping motives. Journal of Retailing, 82, 177-188. https://doi.org/10.1016/j.jretai.2006.05.002

Busnaina, I. (2014). Fashion Marketing in Arab World: Brand Identity vs. Adaptation. Journal of Textile and Apparel, Technology and Management, 9(1), 1-20.

Browne, B. A., \& Kaldenberg, D. O. (1997). Conceptualizing, Self-Monitoring: Links to Materialism and

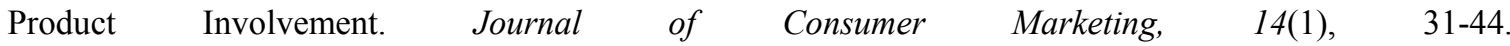
https://doi.org/10.1108/07363769710155848

Bakewell, C., \& Mitchell, V. W. (2003). Generation Y female consumer decision-making styles. International Journal of Retail \& Distribution Management, 31(2), 95-106. https://doi.org/10.1108/09590550310461994

Belton, K., \& Clinton, B. (2007). How society influences young consumers' perceptions of fur and leather goods. Undergraduate Research Journal for the Human Sciences, 6.

Brown, T. A. (2006). Confirmatory factor analysis for applied research. New York: The Guilford Press.

Chiger, S. (2001). Consumer Shopping Survey. Catalog Age, 18(9), 57-60.

Davis, F. (1991). Herbert Blumer and the Study of Fashion: A Reminiscence and a Critique. Symbolic Interaction 14(1), 1-21. https://doi.org/10.1525/si.1991.14.1.1

Delong, M., Bao, M., Wu, J., Chao, H., \& Li, M. (2004). Perception of US branded apparel in Shanghai. $\begin{array}{lll}\text { Journalof Fashion Marketing and } & \text { Management, }\end{array}$ https://doi.org/10.1108/13612020410537843

Evans, M. (1989). Consumer Behavior towards Fashion. European Journal of Marketing, 23(7), 7-16. https://doi.org/10.1108/EUM0000000000575

FashionUnited. (2016). Global fashion industry statistics-International apparel. Retrieved from https://fashionunited.com/global-fashion-industry-statistics

Flynn, L. R., Goldsmith, R. E., \& Kim, W. (2000). A Cross cultural Validation of Three New Marketing Scales for Fashion Research: Involvement, Opinion Seeking and Knowledge. Journal of Fashion Marketing \& 
Management, 4(2), 110-120. https://doi.org/10.1108/eb022583

Goldsmith, R. E., \& Clark, R. A. (2008). An analysis of factors affecting fashion opinion leadership and fashion opinion seeking. Journal of Fashion Marketing and Management, 12(3), 308-322. https://doi.org/10.1108/13612020810889272

Kacen, J. J. (2000). Girrrl power and boyyy nature: the past, present, and paradisal future of consumer gender identity. Marketing Intelligence and Planning, 18(6-7), 45-60. https://doi.org/10.1108/02634500010348932

Kuruvilla, S. J, Nishank, J., \& Nidhi, S. (2009). Do men and women really shop differently? An exploration of gender differences in mall shopping in India. International Journal of Consumer Studies, 33, 715-723. https://doi.org/10.1111/j.1470-6431.2009.00794.x

Krugman, H. E. (1965). The impact of television advertising: Learning without involvement. Public Opinion Quarterly, 29, 349-356. https://doi.org/10.1086/267335

Kim, H. S. (2005). Consumer profiles of apparel product involvement and values. Journal of Fashion Marketing and Management, 9(2), 207-220. https://doi.org/10.1108/13612020510599358

Kline, R. B. (2011). Principles and Practice of Structural Equation Modeling. New York, NY: Guilford Press.

Khan, N., Syed, H., Razavi, R., Hong, Y. H., \& Tan, B. C. (2015). Causal Relationships among Dimensions of Consumer-Based Brand Equity and Purchase Intention: Fashion Industry. International Journal of Business and Management, 10(1), 172-181.

Loewenthal, K. M. (1996). An introduction to psychological tests and scales. London: UCL Press.

Michaelidou, N., \& Dibb, S. (2006). Product involvement: An application in clothing. Journal of Consumer Behavior, 5, 442-453. https://doi.org/10.1002/cb.192

Hogg, M. K., \& Hill, A. J. (1998). Fashion brand preferences among young consumers. International Journal of Retail \& Distribution Management, 26(8), 293-205. https://doi.org/10.1108/09590559810231742

Marciniak, R., \& Mohsen, M. G. (2014). Homogeneity in luxury fashion consumption: an exploration of Arab Women. The Business \& Management Review, 5(1), 32-41.

MENA Design Outlook. (2015). Published by Dubai Design and Fashion Council.

McKinsey Fashion Scope. (2017). The State of Fashion (p. 25).

Nunnally, J. C. (1978). Psychometric theory (2nd ed.). New York: McGraw-Hill Book Company.

O'Cass, A. (2000). An assessment of consumers' product, purchase decision, advertising and consumption involvement in fashion clothing. Journal of Economic Psychology, 21(1), 545-576. https://doi.org/10.1016/S0167-4870(00)00018-0

O'Cass, A. (2004). Fashion clothing consumption: Antecedents and consequences of fashion clothing involvement. European Journal of Marketing, 38(7), 869-882. https://doi.org/10.1108/03090560410539294

O'Cass, A., \& Choy, E. (2008). Chinese generation Y consumers' involvement in fashion clothing. Journal of Product and Brand Management, 17(5), 341-352. https://doi.org/10.1108/10610420810896095

Omair, K., (2009). Arab women managers and identity formation through clothing. Gender in Management: An International Journal, 24(6), 412-443. https://doi.org/10.1108/17542410910980397

Trainer, S. (2015). Piety, Glamour, and Protest: Performing Social Status and Affiliation in the United Arab Emirates. Journal of Contemporary Ethnography, 1-26.

Tigert, D. J., Ring, L. J., \& King, C. W. (1976). Fashion Involvement and Buying Behavior: A Methodological Study. Advances in Consumer Research, 3(1), 50-51.

Teo, T., Tsai, L. T., \& Yang, C. C. (2013). Chapter 1-applying structural equation modeling (SEM) in educational research: an introduction. In M. S. Khine (Ed.), Application of Structural Equation Modeling in Education Research and Practice (pp. 3-21). Rotterdam and Amsterdam: Sense Publishers.

$\begin{array}{llll}\text { Re-positioning Dubai, } & \text { Not-Just-a-Label. } & \text { (2013). } & \text { Retrieved }\end{array}$ https://www.notjustalabel.com/editorial/re-positioning-Dubai

Rahman S., Salman S., Sana A., Tajamal A., \& Muhammad A. K. (2014). Consumers' Adoption of Apparel Fashion: The Role of Innovativeness, Involvement, and Social Values. International Journal of Marketing Studies, 6(3), 49-64. https://doi.org/10.5539/ijms.v6n3p49 
Rocha, M. A. V. (2005). Age, gender and national factors in fashion consumption. Journal of Fashion Marketing and Management, 9(4), 380-390. https://doi.org/10.1108/13612020510620768

Sandra, M., Correia, L., Inês, C., \& Padma, P. (2017). A passion for fashion: the impact of social influence, vanity and exhibitionism on consumer behavior. International Journal of Retail \& Distribution Management, 45(5), 22-36.

Sproles, G. B. (1974). Fashion Theory: A Conceptual Framework. Advances in Consumer Research, 1, 463-472.

Women's Wear Daily. (2015). Fashion Dictionary. Women's Wear Daily (WWD) [referenced 04 November 2015]. Retrieved from http://wwd.com/fashiondictionary

Wilson, E. (1985). Adorned in Dreams: Fashion and Modernity. New Brunswick, NJ: Rutgers University Press.

Wiedmann, K. P., Hennigs, N., \& Siebels, A. (2009). Value-based segmentation of luxury consumption behavior. Psychology and Marketing, 26(7), 625-651. https://doi.org/10.1002/mar.20292

Valter, A. V. (2008). An extended theoretical model of fashion clothing involvement. Journal of Fashion Marketing and Management, 13(2), 179-200.

Vel, K., Captain, A., Al-Abbas, R., \& Al Hashemi, B. (2011). Luxury buying in the United Arab Emirates. Journal of Business and Behavioral Sciences, 23(3), 145-160.

\section{Appendix A}

\section{Fashion Involvement}

\begin{tabular}{|c|c|c|c|c|c|c|}
\hline No. & Items & $\begin{array}{l}\text { Strongly } \\
\text { Disagree }\end{array}$ & Disagree & Neutral & Agree & $\begin{array}{l}\text { Strongly } \\
\text { Agree }\end{array}$ \\
\hline 1 & Fashion clothing is a significant part of my life & & & & & \\
\hline 2 & I think about fashion clothing a lot & & & & & \\
\hline 3 & I am very much involved in/with fashion clothing & & & & & \\
\hline 4 & I find fashion clothing a very relevant product in my life & & & & & \\
\hline 5 & $\begin{array}{l}\text { When I must choose between the two I usually dress for } \\
\text { fashion, not comfort }\end{array}$ & & & & & \\
\hline 6 & I talk all time with my friends on new fashion trends & & & & & \\
\hline
\end{tabular}

\section{Fashion Awareness}

\begin{tabular}{|c|c|c|c|c|c|c|}
\hline No. & Items & $\begin{array}{l}\text { Strongly } \\
\text { Disagree }\end{array}$ & Disagree & Neutral & Agree & $\begin{array}{l}\text { Strongly } \\
\text { Agree }\end{array}$ \\
\hline 1 & I like to update myself about new fashion on daily basis & & & & & \\
\hline 2 & $\begin{array}{l}\text { I can recognize fashion brands quickly among other } \\
\text { competing brands. }\end{array}$ & & & & & \\
\hline 3 & $\begin{array}{l}\text { I use information that comes from others (friends, online } \\
\text { reviews and social media) to keep in style. }\end{array}$ & & & & & \\
\hline 4 & I tend to pay attention to what others are buying & & & & & \\
\hline 5 & $\begin{array}{l}\text { I like to know what brands and products make good } \\
\text { impressions on others. }\end{array}$ & & & & & \\
\hline 6 & I can quickly recall the symbol or logo of new fashion & & & & & \\
\hline
\end{tabular}

\section{Copyrights}

Copyright for this article is retained by the author(s), with first publication rights granted to the journal.

This is an open-access article distributed under the terms and conditions of the Creative Commons Attribution license (http://creativecommons.org/licenses/by/4.0/). 